\title{
CORRECTION
}

View Article Online

View Journal I View Issue

Check for updates

Cite this: RSC Adv., 2020, 10, 19463

\section{Correction: Modelling and prediction of the thermophysical properties of aqueous mixtures of choline geranate and geranic acid (CAGE) using SAFT- $\gamma$ Mie}

\author{
Silvia Di Lecce, $\mathbb{D} \dagger^{\mathrm{a}}$ Georgia Lazarou, ${ }^{a}$ Siti H. Khalit, ${ }^{a}$ David Pugh, $+^{\mathrm{b}}$ \\ Claire S. Adjiman, (D) ${ }^{a}$ George Jackson, (D) ${ }^{a}$ Amparo Galindo (iD) ${ }^{* a}$ and Lisa McQueen ${ }^{c}$ \\ Correction for 'Modelling and prediction of the thermophysical properties of aqueous mixtures of choline \\ geranate and geranic acid (CAGE) using SAFT- $\gamma$ Mie' by Silvia Di Lecce et al., RSC Adv., 2019, 9, 38017- \\ 38031. DOI: 10.1039/C9RA07057E
}

DOI: $10.1039 / \mathrm{d}$ Ora90058c

rsc.li/rsc-advances

The authors regret the omission of one of the authors, David Pugh, from the original manuscript. The corrected list of authors and affiliations for this paper is as shown here.

In addition, we point readers to ref. 1 and 2, together with ref. 17-21 in the original paper, for a complete description of the association contribution to the SAFT- $\gamma$ Mie equation of state.

The authors also wish to correct a number of typographical errors in Tables 3 and 4 . The corrected Tables 3 and 4 are shown below; the letters and numbers in bold indicate the corrected values.

The Royal Society of Chemistry apologises for these errors and any consequent inconvenience to authors and readers.

\footnotetext{
${ }^{a}$ Department of Chemical Engineering, Centre for Process Systems Engineering, Institute for Molecular Science and Engineering, South Kensington Campus, Imperial College London, London SW7 2AZ, UK. E-mail: a.galindo@imperial.ac.uk

${ }^{b}$ Department of Chemistry, Molecular Sciences Research Hub, White City Campus, Imperial College London, London W12 OBZ, UK

${ }^{c}$ Chemical Development, GSK, 1250 S Collegeville Rd, Collegeville, PA, 19426, USA

$\dagger$ Current address: Department of Chemistry, Molecular Sciences Research Hub, White City Campus, Imperial College London, London W12 0BZ, UK.

‡ Current address: Kings College London, Department of Chemistry, Britannia House, 7 Trinity Street, London SE1 1DB, UK.
} 
Table 3 Unlike dispersion interaction energies $\left(\varepsilon_{\mathrm{kl}} / k_{\mathrm{B}}\right) / K$ and repulsive exponents $\lambda_{\mathrm{kl}}^{r}$ for use within the SAFT- $\gamma$ Mie group-contribution approach. $\mathrm{CR}$ indicates a combining rule is used to determine the value of the corresponding parameter. The unlike dispersion interactions indicated with $\mathrm{CR}$ are calculated using eqn (7) for uncharged groups and eqn (10) for charged groups. The combining rule is used to determine the value of $\lambda_{\mathrm{kl}}^{r}$ is given in eqn (6). The unlike group diameters $\sigma_{\mathrm{kl}}$ are obtained using the combining rule given in eqn (5) in all cases

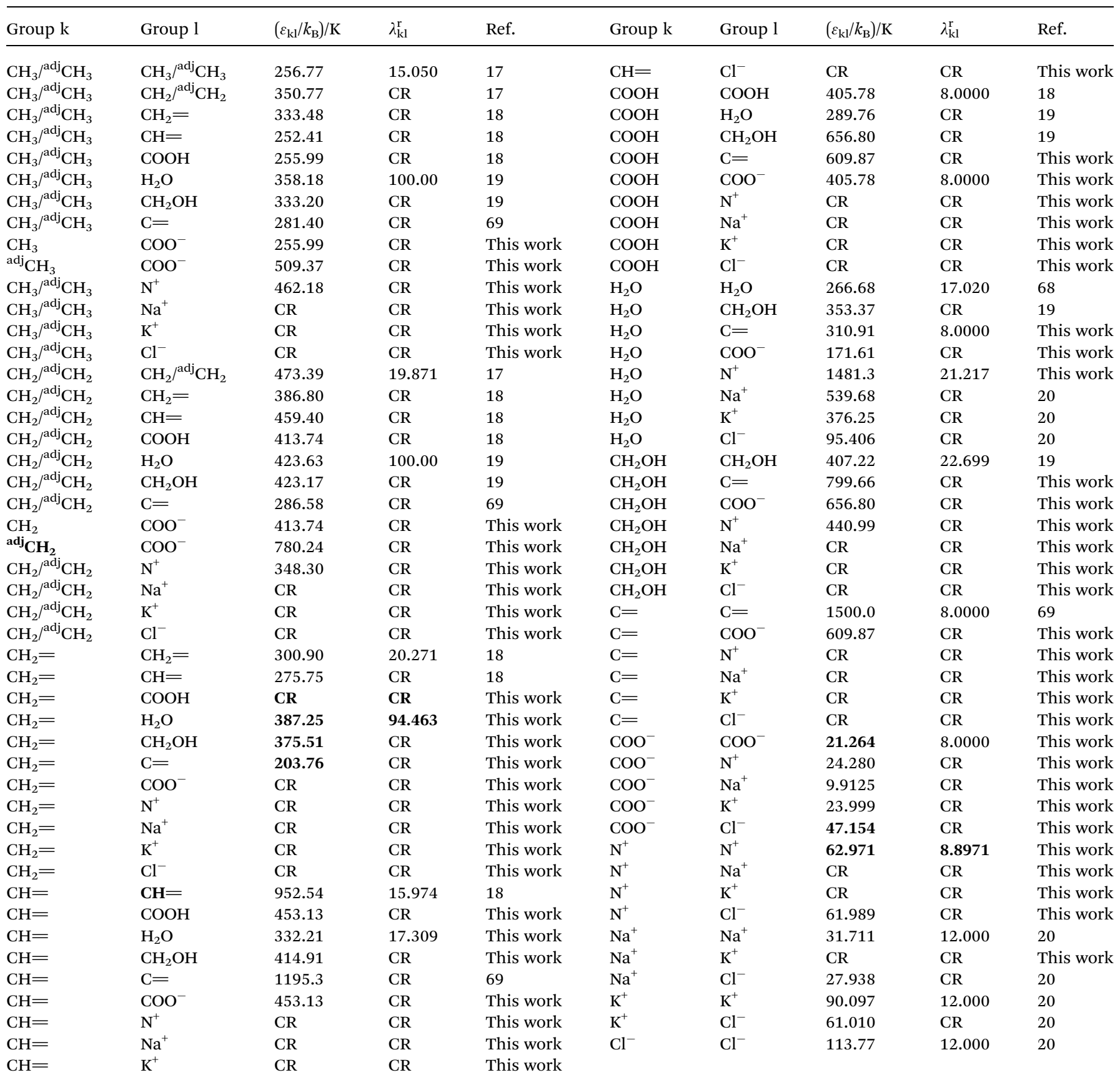


Table 4 Association energy $\varepsilon_{\mathrm{ab}, \mathrm{kl}}^{\mathrm{HB}} / k_{\mathrm{B}}$ and bonding volume $K_{\mathrm{ab}, \mathrm{kl}}^{\mathrm{HB}}$ parameters for use within the SAFT- $\gamma$ Mie group-contribution approach. For groups with several site types, the interactions are symmetrical, i.e., $\varepsilon_{\mathrm{ab}, \mathrm{kl}}^{\mathrm{HB}}=\varepsilon_{\mathrm{ba}}^{\mathrm{HB}}$, Interactions not reported here are set to zero

\begin{tabular}{|c|c|c|c|c|c|c|}
\hline $\mathrm{COOH}$ & $\mathrm{H}$ & $\mathrm{COOH}$ & $\mathrm{H}$ & 6427.9 & 0.8062 & 18 \\
\hline $\mathrm{COOH}$ & $\mathrm{e}_{2}$ & $\mathrm{H}_{2} \mathrm{O}$ & $\mathrm{H}$ & 1252.6 & 150.98 & 19 \\
\hline $\mathrm{COOH}$ & $\mathrm{H}$ & $\mathrm{H}_{2} \mathrm{O}$ & $e_{1}$ & 2567.7 & 270.09 & 19 \\
\hline $\mathrm{COOH}$ & $\mathrm{e}_{1}$ & $\mathrm{CH}_{2} \mathrm{OH}$ & $\mathrm{H}$ & 1015.5 & 21.827 & 19 \\
\hline $\mathrm{H}_{2} \mathrm{O}$ & $\mathrm{e}_{1}$ & $\mathrm{H}_{2} \mathrm{O}$ & $\mathrm{H}$ & 1985.4 & 101.69 & 68 \\
\hline $\mathrm{H}_{2} \mathrm{O}$ & $e_{1}$ & $\mathrm{CH}_{2} \mathrm{OH}$ & $\mathrm{H}$ & 621.68 & 425.00 & 19 \\
\hline $\mathrm{H}_{2} \mathrm{O}$ & $\mathrm{H}$ & $\mathrm{CH}_{2} \mathrm{OH}$ & $e_{1}$ & 2153.2 & 147.40 & 19 \\
\hline $\mathrm{H}_{2} \mathrm{O}$ & $\mathrm{H}$ & $\mathrm{COO}^{-}$ & $e_{1}$ & 802.21 & 52.555 & This work \\
\hline $\mathrm{H}_{2} \mathrm{O}$ & $\mathrm{e}_{1}$ & $\mathrm{~N}^{+}$ & $\mathrm{H}$ & 2783.7 & 15.536 & This work \\
\hline $\mathrm{CH}_{2} \mathrm{OH}$ & $\mathrm{e}_{1}$ & $\mathrm{CH}_{2} \mathrm{OH}$ & $\mathrm{H}$ & 2097.9 & 62.309 & 19 \\
\hline
\end{tabular}

\section{References}

1 S. Dufal, T. Lafitte, A. J. Haslam, A. Galindo, G. N. Clark, C. Vega and G. Jackson, Mol. Phys., 2015, 113, 948-984.

2 S. Dufal, T. Lafitte, A. J. Haslam, A. Galindo, G. N. Clark, C. Vega and G. Jackson, Mol. Phys., 2018, 116, $283-285$. 